\title{
INFLUENCE OF ETHICAL LEADERSHIP ON HEALTH CARE CLIMATE OF INNOVATION IN PAKISTAN
}

\author{
Nida Kamal ${ }^{1}$, Hina Samdani ${ }^{2}$, Batool Zara $^{3}$, Kaynat Kamal ${ }^{4}$
}

${ }^{1}$ Lecturer , Bahria University Islamabad

${ }^{2}$ Senior Assistant Professor, Bahria University Islamabad

${ }^{3}$ Assistant Professor, H.O.D Periodontology, Watim Dental College and Hospital, Rawalpindi

${ }^{4} \mathrm{MS}$ scholar, Health Services Academy, Islamabad

Correspondence: Nida Kamal, Tel: 0925192600022 Ext:298, Email: nida@bui.edu.pk

\begin{abstract}
Background: Health Care Systems face an unprecedented pressure in the 21stcentury. Building and sustaining good health care services and systems remains a challenge throughout the world generally and for developing economies particularly and is known to have a massive impact on the society and ultimately the economic well-being of a nation. This study addresses how Ethical Leadership and its factors of interpersonal justice and informational justice can play a role in fostering the climate of innovation; continuous development and consistency in the healthcare sector.

Methods: The data was collected by administering standard questionnaires for each of the involved variable. The health care industry particularly public and private Hospitals in Pakistan were targeted to collect relevant data. The data analysis was performed through the software for Statistical Package for Social Sciences (SPSS). The analysis included the descriptive analysis, frequencies, reliability analysis, correlation analysis and Regression analysis.

Results: The results state a significant and positive relationship between ethical leadership and climate of innovation in the Health care sector of Pakistan with a significance level $<0.05$.

Conclusion: Given the need for innovation as a solution to the complex challenges faced by health care organizations, ethical leadership plays an important role in promoting climate of innovation in the Health Care sector of Pakistan, which may benefit both the Health care service providers and those who avail the services.

Keywords: Health systems, leadership, innovation, low middle income country
\end{abstract}

\section{Introduction}

In this competitive world health workforce is essential for gaining business competitive advantage. For the continuous improvement of the health care sector, managers, practitioners, and researchers are paying special attention towards the role of ethical leadership. The ethical leadership is responsible for developing health care system that leads to innovative climate that ensures excellent work environment.

In developing countries generally and South Asian region particularly, health care sector has been persistently ignored. Pakistan being one of the key players in the South Asian Economies has also been ignored as far as the development in the health sector is concerned (1). The prevailing two tier system in Pakistan at the provincial and the district level have been termed responsible for taking up assured innovative steps for the provision of good health services and management (2). In the given context, along with the innumerable hurdles and challenges, it is the foremost concern of the health care organizations to ensure that the climate of Innovation shall flourish. Leaders play a pivotal role as a catalyst for providing support, encouragement, sustenance and inspiration for the followers (3).

In this regard, researchers are outing great emphasis on the ever increasing need for critical academic reflections on the role of leadership in the healthcare sector (4). Studies reveal that leadership is becoming significant in the health care sector for the achievement of service outcomes (5). In the scholarly literature, the ethical leadership and the beneficial role it plays the in health care organizations, has started to enjoy progressively added attention as well as debate (6). In health care organizations, leaders have the capacity to influence the ethical environment as well as of the organization in a strong manner, and this consequently inspire employees' behaviour as well as their innovative capabilities (7). However, the enactment of ethical 
leadership necessitates strategies along with the instruments explicit to concrete management of ethical perspectives as well as measurements of the enduring and lasting effects (8). The end result is risk-proofed, innovative organization and stakeholders too (6).

Recent literature on Ethical leadership suggests that it builds a climate of innovation which may be tested by assuming the distinctiveness of the ethical leadership construct (9). It is argued that health care organizations require leadership at all levels and it is indispensable in health care system. Researchers (10) consider that the decline in the performance of the stake holders of the health care system is mainly due to the lack of management and leadership abilities. Researchers investigated and found out a correlation between ethical leadership and these dimensions as a contributor to the organizations innovative climate in the organizations (11).

This research aims to study how Ethical Leadership and its factors of interpersonal justice and informational justice can play a role in fostering the climate of innovation; continuous development and consistency in the health-care sector. Thus, the present study will focus on interpersonal justice and informational justice (8) as dimensions of ethical leadership that will foster a climate of innovation. This study will contribute to the existing literature of leadership and climate of innovation by putting emphasis on the uplift of the health care sector.

The concern about the ethical dimension of leadership is growing dramatically because of the various scandals of the corporate world that have ended up in affecting the climate of innovation of the organizations (12). A lot of effort has been done to provide outstanding reviews about the significance of role of ethics in leadership (13). Similarly work of numerous scholars has played an important role in examining leadership from the perspective of decision making (14-16). However, a lot needs to be done and learned about the antecedents as well as consequences of ethical leadership (17).

The debate on ethical Leadership highlights fair treatment, being trustworthy and managing morality as the key components of this construct. Researchers have emphasized that an ethical leader understands and fosters the positive relationship during the management process (18). These positive relationships are built on elements of trust and respect (19). Ethical leadership in to two behavioral components; one, the leader must make ethical decisions and second, they must be ethical in their interactions and attitudes (20). It also creates a supportive pillar for the use of social exchange theory as the members of an organization replicate the actions of their leaders (21). The Organizational justice, however, is the most closely linked concept to fairness in treatment. The components of the organizational justice are usually linked with opinions related to three types; fairness correlated to the distributive justice (22), Procedural (23) and Interactional justice (24). Therefore, this study uses the dimensions of organizational justice (Interpersonal and Interactional justice) to elaborate the independent variable i.e Ethical Leadership.

The present study adopted the framework based on the social learning theory (21) and the Social Exchange Theory (25) as these theories are based on the norms focusing on reciprocity $(26,27)$. It is referred that when employee believe that they are taken care of in a fair manner, they are most likely to reciprocate the same positive behaviour in the organization and towards others and the one who initiates the behaviour. The social learning theory also suggests that the ethical leadership or ethical leader behavior trickles down to the employees, encouraging them to replicate the same (28).

Interpersonal justice is considered as a social dimension that relates to the management of individuals in a respectable and a socially sensitive manner by individuals who are in charge for carrying out the communication procedures (29). Interpersonal justice as a sub part of the interactional justice has been discussed in the studies (30). Whereas, the impact of the interactional justice on social exchange with the supervisors and thus, we are also arguing the relevance of the interpersonal justice with examination of the supervisor and subordinate relationship (31).

Frequent interactions of subordinates with their supervisors make the influence of interpersonal justice more significant (32). These interactions involve communicating, treating with respect, honesty and dignity in organizational affairs. Alternatively, it can be said that the supervisors who carry out ethical conduct and follow the accepted norms and standards will more likely be perceived as fair in interactional relationship. Ethical leaders, who are also in the supervisory role keep their actions consistent with their words and serve as role models (33). These leaders are perceived as kind, respectful, polite, and honest and influence the followers' perceptions of fair treatment. There is little empirical evidence exists regarding the role of ethical leaders linked to the perception of justice, other studies have taken ethical leadership in the context of transformational leadership (34) and servant leaders (35).

The informational justice refers to the communication of information regarding the procedures of distribution on resources within an organization and as to why they were distributed in particular manner. Informational justice is also the delivery of related information to the organization's employees (36).

Innovation and creativity is interrelated and innovation cannot exist without creativity, as creativity serves as a seed for innovations to grow but it needs to be useful also. Climate and culture of an organization also have an effect on all the levels of innovation (37). Cultural aspect of an organization refers to shared values, principles as well as attitudes while climate refers to shared insights of the work setting. In order to measure organizational climate objective as well as perceptual approaches have 
been used (38). However, an instrument to measure creative climate and its association with innovation; which has further been used in studies to measure climate for innovation has been developed (39). There are two main dimensions of climate of innovation; the Consistency and Continuous Development (11).

Consistency is considered to have elements of continuous learning and development. These factors are necessary for all the innovative organizations to cope up with economic uncertainties and sustain their growth and development in the competitive global market (40). Consistent ethical behaviour of a leader contributes toward creating an environment that has reduced uncertainties and ambiguities and cultivates an environment where individuals can experiment with a variety of methods to completing a task (41).

Continuous Development encourages employees to voice their questions, raise concerns and experiment to attain the strategic objectives of the organization (38). Individuals in an innovate climate in the organization do not become frustrated by continuous development through ongoing experimentation and welcome the associated challenges. Such continuous development also invokes a culture where ethical behaviour prevails in the organization(42).

Creating a climate that supports innovation involves feelings of wellbeing ultimately tend to help flourish creativity (43). In an organization when support for innovation is high then resultant impact of ethical climate of innovation is certainly higher (44). Adding more to it, ethical leadership and innovative work behaviour by employees are also established to be positively correlated with each other (45).

$\mathrm{H1}$ : There is correlation between Ethical Leadership and health care Climate of Innovation.

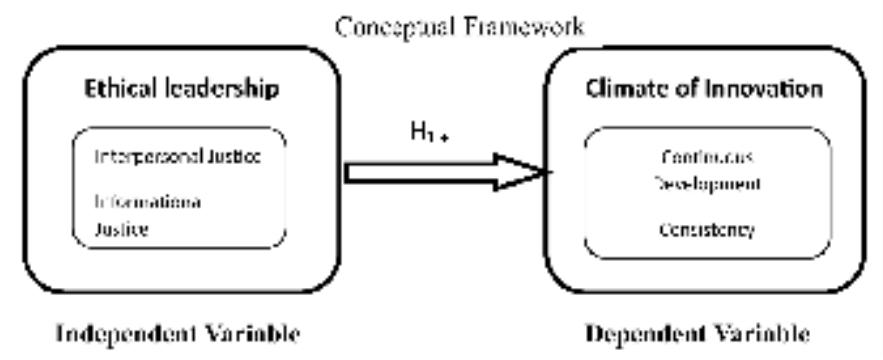

\section{Figure 1. The conceptual framework \\ Methodology}

The present study was conducted using a positivistic research paradigm. The study is descriptive in nature using hypotheses testing model, attempts to find the relationship between ethical leadership (independent variable) and Climate of innovation (dependent variable). Ethical Leadership has been defined the type of leadership in which individuals demonstrate some specific characteristics such as honesty, trustworthiness, fairness, and empathy for the society (46). Climate of Innovation is described as a climate that supports innovation; it cultivates feelings of wellbeing that ultimately tend to initiate and flourish creativity in organizations (43).

The time horizon is cross-sectional and the study was carried out in non-contrived settings. The target population estimate was Physicians from prominent public and private Health care organizations located in the twin cities of Islamabad and Rawalpindi in Pakistan. Using the tables provided by researchers $(47,48)$, a sample size of 300 Physicians was estimated.

The data was collected by administering standard questionnaires for each of the involved variable. The questionnaire on Ethical Leadership (11) and the Innovation climate questionnaire (38) were adopted. The questionnaires are based on a five point likerts scale with 5 as strongly agree to 1 that is strongly disagree. The respondents filled the questionnaire to quantify the items their answers.

A pilot study questionnaire with 40 respondents was also administered in two health care organizations included in the population to check the reliability and validity of the questionnaire. After obtaining the satisfactory feedback from the pilot study results, a total of 300 questionnaires were distributed through convenience sampling method. A total of 120 questionnaires were received back from the same channel after one month indicating a response rate of $40 \%$. Out of these 6 questionnaires were discarded being in non-usable form. Therefore, 114 questionnaires were used as per the requisite sample size.

The data analysis was performed through the software for Statistical Package for Social Sciences (SPSS) version 21. The tests applied through SPSS included Pearson Correlation, ANOVA and Multiple Regression techniques to examine the linear relationship between then independent and the dependent variables. The data analysis and the results are in the ensuing section.

\section{Results}

The descriptive and frequencies (Table-1) shows demographic frequencies of the population in the present study. These included gender and age of the respondents.

Table-1.Demographic profile of the study participants

\begin{tabular}{|l|l|l|l|l|}
\hline \multicolumn{2}{|l|}{ Frequency } & Percent & Std. Dev & Mean \\
\hline Gender & 49 & 43 & .497 & 1.57 \\
\hline Male & 65 & 57 & & \\
\hline Female & 48 & 42 & .931 & 2.02 \\
\hline Age & 16 & 14 & & \\
\hline 25-30 years & 50 & 44 & & \\
41-40 years or above & & & & \\
\hline
\end{tabular}

In the present study, the demographic characteristics were not considered in relation to the variables of interest as the main aim was to find out the relationships among independent and dependent variables. However, Table 1 shows that the sample composed of $43 \%$ males and $57 \%$ females, of which around $42 \%$ were of age 
group 25-30 years, 14 were in the $31-40$ years category and about 44 were of ages 41 or above working in the private and public health care sectors of Rawalpindi and Islamabad.

The Pearson correlation test (Table-2) was used to find out the correlation between the variables along with the Cronbach's ? value (Table-2) to assess the reliability of the instruments used.

Table-2. Means. Standard Deviation, correlation and reliability

\begin{tabular}{|l|l|l|l|l|}
\hline Variables & Mean & Std. Dev & 1 & 2 \\
\hline $\begin{array}{l}\text { Ethical } \\
\text { Leadership }\end{array}$ & 29.4 & 5.48 & 1 & \\
\hline $\begin{array}{l}\text { Climate of } \\
\text { Innovation }\end{array}$ & 40.2 & 3.01 & $.376^{* *}$ & 1 \\
\hline $\begin{array}{l}\text { Cronbach's Alpha } \\
\text { ** Correlation is significant at 0.01 level (2-tailed). }\end{array}$ & .482 & & & \\
\hline
\end{tabular}

Table 2 shows that the values of mean and standard deviation of the responses. The Cronbach's Alpha found through the Pearson's Correlation was 0.482 with significance at the 0.01 level.

The linear regression was conducted to rest the association between Ethical Leadership and Climate of Innovation.

Table-3.Regression analysis

\begin{tabular}{|l|l|l|l|l|l|}
\hline & Coefficient & SE & $t$ & $P$ & $R^{2}$ \\
\hline $\begin{array}{l}\text { Model 1: } \\
\text { Ethical Leadership on Climate } \\
\text { of Innovation }\end{array}$ & .207 & .048 & 4.293 & $.000^{* *}$ & .141 \\
\hline ** Correlation is significant at 0.01 level (2-tailed). \\
\hline
\end{tabular}

The results in Table- 3 state the association between ethical leadership (independent variable) and Climate of innovation (dependent variable) through the regression analysis. It verifies the significant positive relationship between the two variables. The analysis shows that The $F$ statistic value is $F(1,113)=18.429$, which shows the significance of the regression model. The value is one which shows that the null hypothesis has been rejected and the relational hypothesis has been accepted.

The R2=0.141in this analysis which states the coefficient of determination and goodness of fit and shows that 14.1 percent change in the Climate of innovation is brought by the ethical leadership. The beta value $b=0.207$ shows the magnitude of the relationship and that the relationship is significant and positive. The t statistic value in the table is $t=4.293$, which elaborates the precision of the regression coefficient and the value must be $>2$. The overall significance can be seen through the $P$ value. The $P$ value in this table is $p=.000$ $<0.001$, which shows that the study is significant at $99 \%$ level. It overall, shows a positive and significant relationship between the independent (Ethical Leadership) and the dependent (Climate of innovation) variable. This means that with a rise in the ethical leadership behavior of the physicians in the health care organizations, the climate of innovation also tends to increase. This is not only beneficial for the organization itself but the society at large.

\section{Discussion}

The results of the study state a significant and positive relationship between ethical leadership and climate of innovation. This relationship has also been advocated literature (44), that within an organization when support for innovation is high then resultant impact of ethical climate of innovation is higher. Adding more to it, ethical leadership and innovative work behaviour by employees are also established to be positively correlated with each other (45). Given the need for innovation as a solution to the complex challenges faced by health care organizations, ethical leadership needs to play an important role in promoting climate of innovation. This will expose the organization's diverse employees to an environment filled with high creative abilities, which pose different organizational roles, with new kinds of information, and diverse viewpoints and resultantly the employees will evince a stronger link to organizational creativity. Consequently, ethical leadership of the organizations should try to boost climate for innovation right from the start by anchoring such norms in their organizations' visions and missions and by promoting their importance in everyday routine. Finally this study broadens the scope of the existing literature available on ethical leadership and climate of innovation.

\section{Conclusion}

The results are partially generalizable as the study has been conducted on Physicians in the Health care sector of Pakistan. The study may also have self-report bias through the respondent's generated answers. Underlying dimensions of climate of innovation that may come from intrinsic or extrinsic factors can also be researched upon. The study was cross-sectional due to limited time and resources. Future studies may aim to eliminate this bias, work with a longitudinal frame of data collection to study the effect of time. Researchers may also work with a larger sample size and draw comparisons between the public and private sector Health care organizations.

\section{References}

1. Nishtar S, Boerma T, Amjad S, Alam AY, Khalid F, ul Haq I, Mirza YA. Pakistan's health system: performance and prospects after the 18th Constitutional Amendment. The Lancet. 2013 Jun 22;381(9884):2193-206.

2. Khan ZA, Nawaz D, Khan I. The impact of leadership styles on innovation in health services. Gomal University Journal of Research. 2015 Jun 1;31(1).

3. Agbor E. Creativity and innovation: The leadership dynamics. Journal of Strategic Leadership. 2008;1(1):39-45.

4. Gabriele EF. Ethics Leadership in Research, Healthcare and Organizational Systems: Commentary and Critical Reflections. Journal of 
Research Administration. 2011;42(1):88-102.

5. Edmonstone J. Developing leaders and leadership in health care: a case for rebalancing? Leadership in Health Services. 2011 Feb 8;24(1):8-18.

6. Agheorghiesei Corodeanu Dt, Poroch V. A possible theoretical model of ethical system management in healthcare institutions. In6th LUMEN International Conference on Rethinking Social Action Core Values 2015 Apr (pp. 16-19).

7. Den Hartog DN. Ethical leadership. Annu. Rev. Organ. Psychol. Organ. Behav.. 2015 Apr 10;2(1):409-34.

8. Mayer DM, Aquino K, Greenbaum RL, Kuenzi M. Who displays ethical leadership, and why does it matter? An examination of antecedents and consequences of ethical leadership. Academy of Management Journal. 2012 Feb;55(1):151-71.

9. Chen AS, Hou YH. The effects of ethical leadership, voice behavior and climates for innovation on creativity: A moderated mediation examination. The Leadership Quarterly. 2016 Feb 1;27(1):1-3.

10. Buchanan DA, Fitzgerald L, Ketley D, editors. The sustainability and spread of organizational change: modernizing healthcare. Routledge; 2006 Dec 5.

11. Crosley V. Empirical study on the relationship between ethical leadership and organizational climate of innovation. 2014

12. Stone AG, Patterson K. The history of leadership focus. InServant Leadership Research Roundtable Proceedings 2005Aug.

13. Brown ME, Treviño LK. Ethical leadership: A review and future directions. The leadership quarterly. 2006 Dec 1;17(6):595-616.

14. Butterfield KD, Trevin LK, Weaver GR. Moral awareness in business organizations: Influences of issue-related and social context factors. Human relations. 2000 Jul;53(7):9811018.

15. Trevino LK. Ethical decision making in organizations: A person-situation interactionist model. Academy of management Review. 1986 Jul 1;11(3):601-17.

16. Treviño LK, Weaver GR. Organizational justice and ethics program "follow-through": Influences on employees' harmful and helpful behavior. Business Ethics Quarterly. 2001 Oct;11(4):65171.

17. Brown ME, Mitchell MS. Ethical and unethical leadership: Exploring new avenues for future research. Business Ethics Quarterly. 2010 Oct;20(4):583-616.

18. Brown ME, Treviño LK, Harrison DA. Ethical leadership: A social learning perspective for construct development and testing.
Organizational behavior and human decision processes. 2005 Jul 1;97(2):117-34.

19. Khuong MN, Quoc HT. The effects of organizational justice and ethical leadership on employee performance in Binh Duong's Industrial Parks, Vietnam'. Journal of Economics, Business and Management. 2016;4(4):327-33.

20. Rawls J. A Theory of Justice (1971). na; 1999.

21. Bandura A. Self-efficacy: toward a unifying theory of behavioral change. Psychological review. 1977 Mar;84 (2):191.

22. Adams JS. Inequity in social exchange. In Advances in experimental social psychology 1965 Jan 1 (Vol. 2, pp. 267-299). Academic Press.

23. Lind EA, Tyler TR. The social psychology of procedural justice. Springer Science \& Business Media; 1988 Feb 29.

24. Bies RJ. Interactional (in) justice: The sacred and the profane. Advances in organizational justice. 2001;85:108.

25. Blau P. Exchange and power in social life. Routledge; 2017 Sep 29.

26. Gouldner HP. Dimensions of organizational commitment. Administrative Science Quarterly. 1960 Mar 1:468-90.

27. Levinson H. Reciprocation: The relationship between man and organization. Administrative science quarterly. 1965 Mar 1:370-90.

28. Mayer DM, Kuenzi M, Greenbaum R, Bardes M, Salvador RB. How low does ethical leadership flow? Test of a trickle-down model. Organizational behavior and human decision processes. 2009 Jan 1;108(1):1-3.

29. Colquitt JA. On the dimensionality of organizational justice: A construct validation of a measure. Journal of applied psychology. 2001 Jun;86(3):386.

30. Bies RJ. Are procedural justice and interactional justice conceptually distinct?. 2005

31. Rupp DE, Cropanzano R. The mediating effects of social exchange relationships in predicting workplace outcomes from multifoci organizational justice. Organizational Behavior and Human Decision Processes. 2002 Sep 1;89(1):925-46.

32. Moorman RH. Relationship between organizational justice and organizational citizenship behaviors: Do fairness perceptions influence employee citizenship?. Journal of applied psychology. 1991 Dec;76(6):845.

33. Yukl G, Mahsud R, Hassan S, Prussia GE. An improved measure of ethical leadership. Journal of leadership \& organizational studies. 2013 Feb;20(1):38-48.

34. Cho J, Dansereau F. Are transformational leaders fair? A multi-level study of 
transformational leadership, justice perceptions, and organizational citizenship behaviors. The Leadership Quarterly. 2010 Jun 1;21(3):409-21.

35. Mayer DM, Bardes M, Piccolo RF. Do servantleaders help satisfy follower needs? An organizational justice perspective. European Journal of Work and Organizational Psychology. 2008 Jun 1;17(2):180-97.

36. Greenberg J. Stealing in the name of justice: Informational and interpersonal moderators of theft reactions to underpayment inequity. Organizational behavior and human decision processes. 1993 Feb 1;54(1):81-103.

37. Mathisen GE, Einarsen S. A review of instruments assessing creative and innovative environments within organizations. Creativity Research Journal. 2004 Mar 1;16(1):119-40.

38. Siegel SM, Kaemmerer WF. Measuring the perceived support for innovation in organizations. Journal of Applied Psychology. 1978 Oct;63(5):553.

39. Amabile TM. A model of creativity and innovation in organizations. Research in organizational behavior. 1988 Jan 15;10(1):123-67.

40. Buckler B. Practical steps towards a learning organisation: applying academic knowledge to improvement and innovation in business processes. The Learning Organization. 1998 Mar 1;5(1):15-23.

41. Foglia MB, Cohen JH, Pearlman RA, Bottrell MM, Fox E. Perceptions of ethical leadership and the ethical environment and culture: Integrated Ethics TM Staff Survey data from the VA health care system. AJOB Primary Research. 2013 Jan 1;4(1):44-58.

42. Chen AY, Sawyers RB, Williams PF. Reinforcing ethical decision making through corporate culture. Journal of Business Ethics. 1997 Jun 1;16(8):855-65.

43. Thiroux JP, Krasemann KW. Ethics: Theory and practice. Pearson Prentice Hall; 2007.

44. Kwon Choi B, Koo Moon H, Ko W. An organization's ethical climate, innovation, and performance: Effects of support for innovation and performance evaluation. Management Decision. 2013 Jun 21;51(6):1250-75.

45. Yidong T, Xinxin L. How ethical leadership influence employees' innovative work behavior: A perspective of intrinsic motivation. Journal of business ethics. 2013 Aug 1;116(2):441-55.

46. Brown ME, Treviño LK. Do role models matter? An investigation of role modeling as an antecedent of perceived ethical leadership. Journal of Business Ethics. $2014 \mathrm{Jul}$ 1;122(4):587-98.

47. Krejcie RV, Morgan DW. Determining sample size for research activities. Educational and psychological measurement. 1970
Sep;30(3):607-10.

48. Sekaran U, Bougie R. Research methods for business: A skill building approach. John Wiley \& Sons; 2016 Jun 27. 